\title{
A construção do número e a sequência numérica oral nas práticas de professores da educação infantil
}

\author{
Heloise de Araujo Albuquerque \\ Ophelio Walkyrio de Castro Walvy \\ Gabriela dos Santos Barbosa
}

\section{Resumo}

O objetivo deste trabalho é identificar o papel que professores da Educação Infantil atribuem à sequência numérica oral no processo de construção e aquisição do conceito de número. Os resultados que apresentamos são parte de uma pesquisa mais ampla que permitiu a formação continuada de professores da Educação Infantil e a elaboração de um material de apoio destinado a estes professores que permite repensar sobre a importância da aquisição da sequência numérica oral para a construção do conceito de número pelas crianças. Para contemplar nosso objetivo, realizamos uma pesquisa de campo que envolveu observação de práticas e entrevistas semiestruturadas com um grupo de quatro professoras de uma creche municipal de Duque de Caxias, Baixada Fluminense/RJ. Analisamos os dados a luz das ideias de Piaget e seus seguidores. Nossos dados sugerem que as práticas e concepções sobre a sequência numérica oral estão estreitamente relacionadas às práticas e concepções sobre o processo de conceitualização do número e estas, por sua vez, sofrem influência das relações que as professoras estabelecem com a própria Matemática. Daí a necessidade de um programa de formação continuada para o grupo pesquisado.

Palavras-chave: Educação Infantil. Número. Sequência Numérica Oral. 


\title{
The construction of number and oral numerical sequence in the practices of teachers of kindergarten
}

\author{
Heloise de Araujo Albuquerque \\ Ophelio Walkyrio de Castro Walvy \\ Gabriela dos Santos Barbosa
}

Abstract

The objective of this work is to identify the role that kindergarten teachers attribute to the oral numerical sequence in the process of construction and acquisition of the number concept. The results that we present are part of a broader research that allowed the continuing education of Early Childhood teachers and the elaboration of a support material for these teachers that allows to rethink about the importance of the acquisition of the oral numerical sequence for the construction of the concept Number of children. In order to contemplate our objective, we conducted a field survey that involved observing practices and semi-structured interviews with a group of four teachers from a municipal day care center in Duque de Caxias, Baixada Fluminense/RJ. We analyze the data in light of the ideas of Piaget and his followers. Our data suggest that the practices and conceptions about the oral numerical sequence are closely related to the practices and conceptions about the number conceptualization process and these, in turn, are influenced by the relationships that the teachers establish with Mathematics. Hence the need for a continuing training program for the group being researched.

Keywords: Kindergarten. Number. Sequence Number. 


\section{Introdução}

O objetivo deste trabalho é identificar o papel que professores da Educação Infantil atribuem à sequência numérica oral no processo de construção e aquisição do conceito de número. Os resultados que aqui apresentamos são parte de uma pesquisa mais ampla que permitiu a formação continuada de professores da Educação Infantil e a elaboração de um material de apoio destinado a estes professores que permite repensar sobre a importância da aquisição da sequência numérica oral para a construção do conceito de número pelas crianças.

Desde o seu nascimento, a criança está inserida num mundo onde a Matemática é utilizada como ferramenta simbólica e é na Educação Infantil que terá início a aquisição desta ferramenta e dos modos como utilizá-la. A criança tem o direito de se apropriar da experiência social da humanidade e do conhecimento historicamente acumulado. Esta apropriação é o início de muitas outras conquistas e aprendizagens.

O conhecimento da Matemática é de vital importância na vida da criança, relacionando-se ao processo de investigação e de motivação à descoberta do conhecimento de mundo. Concordando com Moura (2006, p. 12), entendemos a Matemática como "produto da atividade humana e que se constitui no desenvolvimento de solução de problemas criados nas interações que produzem o modo humano de viver socialmente num determinado tempo e contexto".

A Educação Infantil tem suas especificidades e voltamos nossa atenção para ela nesta pesquisa. Por muitos anos, ela foi esquecida em detrimento de outros níveis e modalidades educacionais. Para muitos, a Educação Infantil é somente um lugar onde as crianças ficam para serem cuidadas enquanto suas famílias trabalham, ou seja, um lugar onde as famílias que não têm condições de educar seus filhos, deixam suas crianças diariamente. Entretanto, muito mais do que isso, a Educação Infantil é um espaço educativo onde o educar e o cuidar se atrelam visando à educação integral da criança. Trata-se de um espaço cheio de vida, de curiosidade e inquietações, onde o mundo está por se redescobrir. Espaço este, por sua vez, pertencente à educação básica, devendo o Estado garantir sua oferta gratuita e de qualidade, conforme a Lei de Diretrizes e Bases (LDB), nº9394/96, assegura em seus artigos $29^{\circ}$ e $30^{\circ}$ :

Art. 29 A educação infantil, primeira etapa da educação básica, tem como finalidade o desenvolvimento integral da criança até os seis anos de idade, em seus aspectos físico, psicológico, intelectual e social, complementando a ação da família e da comunidade.

Art. 30 A educação infantil será oferecida em: I - creches ou entidades equivalentes, para crianças de até três anos de idade; II - pré-escolas para crianças de quatro a seis anos de idade (BRASIL, 2005, p. 17). 
Em outras palavras, a LDB estabelece que o atendimento à criança não é um favor e, sim, um dever do Estado. A criança é vista como um ser social, um sujeito de direitos. Com ela, a ideia de democratização do ensino foi ampliada e a educação passou a significar possibilidade de ascensão social, com igualdade de oportunidades para todas as crianças.

Voltado para a organização curricular, em 1998, foi publicado o Referencial Curricular Nacional da Educação Infantil (RCNEI). Ele foi concebido para ser um guia de reflexão educacional aos profissionais que atuam com as crianças de o (zero) a 6 (seis) anos. Trata-se de uma referência nacional para que todos os estados e municípios possam se organizar curricularmente em suas redes de ensino, apresentando, inclusive, propostas de atividades. Segundo ele, as instituições de Educação Infantil podem proporcionar às crianças condições para a aquisição dos novos conhecimentos, entre eles os conhecimentos matemáticos. Assim, a Educação Infantil atende tanto às necessidades próprias das crianças de construírem conhecimento dos diversos campos do saber, como corresponde à necessidade de instrumentá-la para melhor viver, participando e compreendendo o mundo que lhes exigem diferentes conhecimentos e habilidades (BRASIL, 1998).

O RCNEI nos apresenta uma concepção de aprendizagem com base na construção de conhecimento, na perspectiva de que a criança possui suas próprias ideias / hipóteses e que elas se constituem nas interações sociais e no grande esforço para compreender a vida e seus desafios:

No processo de construção do conhecimento, as crianças se utilizam das mais diferentes linguagens e exercem a capacidade que possuem de terem ideias e hipóteses originais sobre aquilo que buscam desvendar. Nessa perspectiva as crianças constroem o conhecimento a partir das interações que estabelecem com as outras pessoas e com o meio em que vivem. $\mathrm{O}$ conhecimento não se constitui em cópia da realidade, mas sim, fruto de um intenso trabalho de criação, significação e ressignificação. (BRASIL, 1998, p.21)

Assim, o RCNEI nos aponta para uma criança ativa que traz para a escola saberes de uma infância própria e particular, de seu universo social e cultural. O professor, por sua vez, precisa acreditar que ela, mesmo muito pequena, pode produzir conhecimento, utilizando e relacionando saberes já construídos. Ele deve incorporar e produzir novas aprendizagens, sendo a criança protagonista de todo o processo.

Em relação à prática do professor no ensino da Matemática, nas especificidades da Educação Infantil, o RCNEI, para sinalizar a necessidade de mudança em relação à concepção de aprendizagem, descreve práticas equivocadas que ainda estão presentes em muitas salas de aulas brasileiras: 
Há uma ideia corrente de que as crianças aprendem não só a Matemática, mas todos os outros conteúdos, por repetição e memorização por meio de uma sequência linear de conteúdos encadeados do mais fácil para o mais difícil. São comuns as situações de memorização de algarismos isolados, por exemplo, ensina-se o 1 , depois o 2 e assim sucessivamente. Propõe-se exercícios de escrita dos algarismos em situações como: passar o lápis sobre numerais pontilhados, colagem de bolinhas de papel crepom sobre numerais, cópias repetidas de um mesmo numeral, escrita repetida da sucessão numérica. (Brasil, 1998, p.209)

Estas práticas ainda se verificam nos dias de hoje. Quando falamos especificamente do ensino da Matemática na Educação Infantil, comumente muitos professores deste segmento se remetem a atividades de cobrir números pontilhados, ao ensino da sequência numérica até o 10 e à valorização da grafia correta dos numerais, bem como de sua dita associação a sua respectiva quantidade, sem levar em conta outras diferentes funções, a saber: posição, codificação e medida. Indo de encontro a essas práticas, Brizuela afirma:

As crianças, nos mais diversos contextos socioeconômicos e culturais, estão imersas em um mundo de notações matemáticas desde o momento em que chegam ao mundo. Os números escritos que as rodeiam representam a grande variedade de conceitos numéricos e quantitativos, além de serem usados para outros propósitos diferentes (por exemplo, como rótulos e em números de telefone. (BRIZUELA, 2006, p.17)

Concordando com Brizuela (2006), entendemos que os números escritos que rodeiam as crianças representam uma grande variedade de conceitos numéricos e quantitativos, além de serem usados para propósitos diferentes. E, com essa perspectiva, investigamos as concepções e práticas de professores da Educação Infantil sobre o processo de construção do número. Acreditamos que a identificação destes elementos pode oferecer diretrizes para a elaboração de programas de formação continuada e de materiais de apoio ao trabalho dos professores. Para explicarmos melhor nossas ideias, nas próximas seções, discorremos sobre, respectivamente, a Matemática na Educação Infantil, o processo de construção e aquisição do número e a sequência numérica oral. Na continuidade, descrevemos nosso método de pesquisa e analisamos os dados que coletamos. Por fim, fazemos uma síntese dos resultados e levantamos questões para pesquisas futuras.

\section{A Matemática e o Número na Educação Infantil}

Desde que nascem, as crianças são inseridas em ambientes em que se mobilizam inúmeros conhecimentos matemáticos. Em resumo, "as crianças, desde o nascimento, estão imersas em um universo do qual os conhecimentos matemáticos são parte integrante" (BRASIL, 1998, p. 207). Mesmo antes de chegar à escola, a criança vivencia diariamente a Matemática. Em casa, na rua, com os amigos, recebem informações reelaborando seus 
conhecimentos e tornando-se, também, produtoras de saberes. Muitas vezes utilizam recursos próprios e pouco convencionais para resolverem as diversas situações problemas que lhes surgem. E tudo o que vivenciam favorece a elaboração dos conhecimentos matemáticos. Mas o que as pesquisas nesta área nos comprovam?

Apresentamos aqui estudos considerados significativos para o ensino de Matemática na Educação Infantil. É importante destacar, apenas, a dificuldade em encontrar estudos e pesquisas nesta área.

Inicialmente cabe mencionar que a noção equivocada de que a Educação Infantil é uma etapa preparatória para o Ensino Fundamental ainda subjaz muitas práticas docentes. Scriptori (2011) alerta que nos espaços de Educação Infantil aumentam as propostas educacionais em que o foco passa a ser a antecipação de conteúdos e a pré-escola vista como etapa de preparação para a educação básica, com o objetivo de que no futuro as crianças obtenham sucesso escolar. Nesse sentido, Panizza (2006) ainda acrescenta que "na Educação Infantil se prioriza o ensino dos conteúdos que, supõe-se, vão ser necessários para que na $1^{\mathrm{a}}$ série os alunos aprendam a fazer as contas, pratiquem-nas até dominá-las e depois as apliquem para resolver problemas" (PANIZZA, 2006, p. 44).

Scriptori (2011) evidencia, então, que no caso do ensino da Matemática, isso é bem pior. Ela menciona a situação de se ensinar conteúdos da Matemática formal, observando essas práticas também para os bebês. Sobre estes fatos, Monteiro (2010) sinaliza que as instituições de Educação Infantil possuem enfoques didáticos diferenciados e, em muitos casos, estes estão apoiados em concepções que se contradizem com as práticas. Tomando como exemplo o ensino de números, ela elucida práticas muito frequentes nas salas de aula da Educação Infantil que preconizam o ensino de um número de cada vez, na sequência, começando do um, enfatizando o treino, o traçado e a percepção. Essa prática se ancora na concepção de que as crianças aprendem por repetição, memorização e associação, não valorizando o conhecimento social construído pelas crianças. Trata-se do enfoque do "ensino clássico" e está inserido nos pressupostos teóricos e filosóficos da pedagogia tradicional, que consideram a criança como uma folha em branco sem conhecimentos anteriores e que, por meio do treino e da repetição, chegará ao produto final extremamente valorizado como conteúdo aprendido. Este fato nega às crianças a oportunidade de refletir e formular hipóteses sobre o sistema de numeração.

Para Monteiro (2010), outra prática equivocada presente no ensino dos números é a que transforma as operações lógicas e as provas piagetianas (tarefas de conservação, seriação e classificação que Piaget utilizou em seus estudos) em conteúdos, propondo atividades de seriar, ordenar, classificar e comparar objetos. Além disso, segundo a autora, entende-se que, para trabalhar com a Matemática, faz-se necessário utilizar material concreto. O uso do 
material concreto como a única maneira para resolver um problema proposto, muitas vezes impede a criança de decidir qual procedimento quer utilizar, como grafar marcas numa folha de papel ou contar nos dedos. Ou, ainda, que a criança vivencie as atividades corporalmente, como sendo um pião num jogo de percurso. Essa concepção baseia-se na ideia de que, para as crianças aprenderem, elas precisam passar por uma resolução concreta, depois gráfica e por final a abstrata.

Entretanto, os estudos de Lerner e Sadovsky (2009) sobre o sistema de numeração decimal comprovam que as crianças formulam hipóteses sobre os números e seu uso em sua vida cotidiana, que não necessariamente se encontram na ordem do mais simples para o mais complexo. Estes autores, bem como Panizza (2006) e Monteiro (2010), reconhecem que as crianças, em suas interações cotidianas, perguntam sobre os números, discutem quem vem antes, quem vem depois, ou que número se apresenta em determinada embalagem. Graças a pesquisas como as citadas no texto, já sabemos que as crianças formulam hipóteses originais sobre os números e sua conceitualização.

Assim, a abordagem da Matemática na Educação Infantil deve ser bastante diferente daquela proposta tradicionalmente. Pesquisas como as de Lerner e Sadovsky (2009), Monteiro (2010), Scriptori (2011) e Mudim e Saramago (2013), salientam que o trabalho de Matemática na Educação Infantil deve surgir nas práticas escolares natural e espontaneamente, estabelecendo relações e tendo como base o dia a dia das crianças. Elas devem ser estimuladas a pensar e a avançar em suas noções a partir dos seus conhecimentos prévios. Enfocam também que é muito importante envolver as crianças na exposição de suas ideias, na interação com os demais colegas. Este deve ser o ponto de partida para a formulação de situações e resoluções de problemas que podem ter origem em uma brincadeira, em uma conversa na roda ou em experiências partilhadas até mesmo fora do ambiente escolar. Como afirma Monteiro (2010, p. 3), "a finalidade central do ensino da Matemática para os pequenos é começar a introduzi-los em um modo próprio de produção de conhecimento, uma parcela da cultura que a escola tem o dever de transmitir." Mas, para isso, é preciso levar as crianças a fazerem o mesmo movimento desenvolvido pelos matemáticos em suas práticas. Assim, acrescenta:

[...] fazer perguntas, procurar soluções, buscar pontos de apoio no que se sabe para encontrar o que não se sabe, experimentar, errar, analisar, corrigir ou ajustar as buscas, comunicar procedimentos e resultados, defender um ponto de vista e considerar a produção dos outros, estabelecer acordos e comprovar. (MONTEIRO, 2010, p. 3)

Nessa perspectiva, Scriptori (2011) nos remete ao principal objetivo da Educação Infantil que é o desenvolvimento global e harmonioso da criança como um todo; ou seja, em 
todos os aspectos: físico, social, cognitivo, afetivo, ético e moral. Para ela, as crianças devem ser impelidas a pensarem e agirem de forma ativa diante das situações cotidianas do ambiente escolar, tornando-se autônomas e críticas diante dos conflitos e problemas que surgem na vida em sociedade. Mudim e Saramago (2013) ainda argumentam que o processo e a capacidade de raciocinar se estabelece na interação e reflexão. Nesse processo, o indivíduo age sobre o objeto tentando compreender sua experiência, construindo assim um caminho para a aprendizagem. Assim, estes autores defendem a interação em variadas situações entre as crianças como forte estratégia para a aquisição dos conhecimentos matemáticos mesmo que de forma implícita.

Restringindo estas noções ao ensino de números e do sistema de numeração, Scriptori (2011) explica que, por trás das formas mais comuns que se têm de se tentar ensinar números na Educação Infantil, está a crença de que o conceito de número pode ser transmitido oralmente e memorizado pela criança por meio de exercícios gráficos. Isso denota um desconhecimento sobre o que seja o conhecimento físico e o conhecimento lógicomatemático e a diferença entre número e numeral. Numeral corresponde às representações gráficas da quantidade enquanto números são relações de ordem psicológicas (e mentais) que estabelecemos entre as quantidades do mundo físico em que vivemos. Por isso, as relações de ordem e de inclusão hierárquica não podem ser transmitidas oralmente. Para que a criança consiga estabelecer tais relações, ela necessita da construção de estruturas mentais específicas que permitam por meio de experimentação ativa a compreensão dessas relações, o que exige compreensão e não memorização. Na próxima seção, refletimos mais detalhadamente sobre o processo de construção do número. Porém, finalizando, cabe destacar o papel do professor nesse processo. É consenso entre Lerner e Sadovsky (2009), Monteiro (2010), Scriptori (2011) e Mudim e Saramago (2013) que o professor exerce um papel fundamental na Educação Infantil. É ele quem vai proporcionar e vivenciar junto às crianças espaços de compreensão e busca.

\section{O conceito de número, a contagem e a sequência numérica oral}

A História da Matemática e, portanto, da humanidade, comprova a necessidade do homem em controlar quantidades. Desta necessidade surge o número. Recordamos a história do pastor que fazia uma marca em seu cajado ou separava uma pedrinha para cada ovelha que tinha em seu rebanho. Essa história exemplifica bem o surgimento de uma operação matemática, a correspondência biunívoca ou correspondência um a um, que reconhecemos como um dos princípios para a contagem.

Quando retomamos o caminho da construção do número pelas crianças, observamos o grau de complexidade deste processo e nos lembramos também do quão complexo foi para 
a humanidade chegar aos sistemas de numeração que conhecemos. As crianças, de certa forma, refazem este caminho quando buscam compreender as regularidades do sistema de numeração decimal. É neste sentido que Kamii (2002) afirma que as crianças podem e devem reinventar a aritmética, pois acredita, assim como Piaget, que o número surge das relações que os indivíduos constroem mentalmente.

Tais relações, por sua vez, encontram-se ligadas a fontes internas e externas do conhecimento, sendo o conhecimento lógico-matemático ligado a fontes internas e os conhecimentos físico e social ligados a fontes externas. Segundo Kamii (2003, p. 15), "a criança progride na construção do conhecimento lógico-matemático pela coordenação das relações simples que anteriormente ela criou entre os objetos" (KAMII, 2003, p. 15).

Esta diferenciação fez com que Piaget (1973) criasse os conceitos de abstração reflexiva ou construtiva e abstração empírica ou simples. A abstração empírica ou simples aponta para a abstração das propriedades a partir dos conhecimentos físico e social que podemos extrair dos objetos (considerada parcialmente externa ao indivíduo). Já a abstração reflexiva envolve a construção de relações entre os objetos, relações estas que existem apenas mentalmente. Como aponta Kamii (2003):

A relação entre os objetos existe somente nas mentes daqueles que podem criá-la. O termo abstração construtiva poderia ser mais fácil de entender do que abstração reflexiva, para indicar que esta abstração é uma construção feita pela mente, em vez de representar apenas o enfoque sobre algo já existente nos objetos (KAMII, 2003, p. 17).

Assim, psicologicamente, nas crianças pequenas, uma abstração não existe sem a outra, pois elas precisam da abstração empírica para a construção do conhecimento lógicomatemático. Kamii (2003) observa que, apenas posteriormente, quando a criança progride na construção de números maiores, é que ela poderá operar mentalmente sem esta dependência.

O número está diretamente ligado à abstração reflexiva uma vez que "o número, de acordo com Piaget (1973), é uma síntese de dois tipos de relações que a criança elabora entre os objetos (por abstração reflexiva). Uma é a ordem e a outra a inclusão hierárquica” (KAMII, 2003, p. 19). Neste caminhar, quando a criança precisa contar um conjunto de objetos, ela vai ordená-los mentalmente para que não pule objetos ou torne a contá-los e, para quantificar um determinado número de objetos, ela precisa ir incluindo hierarquicamente como um em dois, dois em três, três em quatro, e assim sucessivamente. Ao compreender estas relações, a criança demonstra ter construído uma estrutura que a habilita a olhar para um conjunto de objetos numericamente e não espacialmente. 
O processo de construção do número pela criança não é algo fácil e não acontece de modo espontâneo. Para confirmar que o número é uma relação mental criada por cada indivíduo, Piaget desenvolveu a tarefa de conservação ou "prova de conservação", como é mais conhecida no Brasil. Nela, o examinador coloca sobre a mesa certa quantidade (sete ou oito) de fichas de duas cores diferentes. Ele arruma a primeira fileira e pede à criança que coloque o mesmo número de fichas que ele enfileiradas abaixo das suas. Na frente da criança o examinador deixa a primeira fileira como foi arrumada anteriormente. Em seguida, ele comprime a fileira que está abaixo, deixando-a mais curta. Com isso, ele pergunta à criança: "Há quantas fichas vermelhas? Quantas azuis? Onde há mais? Como você sabe?"

Após a aplicação desta prova, foram estabelecidas três fases do desenvolvimento das crianças pequenas até a conservação do número. Na primeira fase as crianças não conseguem fazer um conjunto com o mesmo número de fichas apresentadas pelo examinador, a quantidade é irrelevante e elas usam todas as fichas que lhes forem dadas para formar a fileira. Também nesta fase as crianças que conseguem formar o conjunto com o mesmo número de fichas (geralmente as de quatro anos) utilizam o critério espacial, ou seja, baseiam-se no que elas podem visualizar e, para que as fileiras tenham a mesma quantidade de fichas, basta que tenham o mesmo tamanho.

Na segunda fase as crianças formam uma fileira que contém a mesma quantidade de fichas da fileira dada a priori, utilizando a correspondência biunívoca, mas, quando são perguntadas quantas fichas há em cada fileira, dizem haver mais na fileira que se apresenta visualmente mais longa. Já na terceira fase as crianças dão respostas corretas a todos os questionamentos, demonstrando a capacidade de conservar o número. A conservação de número "refere-se a nossa capacidade de deduzir, por meio de raciocínio lógico-matemático, que a quantidade de uma coleção permanece a mesma quando seu arranjo espacial e sua aparência empírica são alterados.” (KAMII, 2002, p. 18).

A partir das provas de conservação, Piaget considera que as crianças entre cinco e seis anos podem vir a conservar quantidades discretas, mas o entendimento de que todos os números consecutivos estão conectados pela operação + 1, que é a realização da síntese entre a inclusão hierárquica e a ordem, acontece somente aos sete ou oito anos de idade.

Os estudos de Piaget e Szeminska (1975) permitem ainda que Kamii reitere que "a construção do número acontece gradualmente por 'partes', em vez de tudo de uma vez. A primeira parte vai até aproximadamente 7 , a segunda até 8-15 e a terceira até 15-30" (KAMII, 2003, p. 31). Nesse estudo, a autora ressalta ainda a importância de se facilitar o desenvolvimento dos processos cognitivos que tecem a construção dos pequenos números. Segundo ela, se as crianças forem desafiadas a colocar todos os tipos de coisas em todos os 
tipos de relações, elas se tornarão ativas e prosseguirão neste caminho para completar a estruturação da série numérica.

Vergnaud (2009), em conformidade com Kamii (2003), considera que a noção de número é o conhecimento mais importante da Matemática ensinada na escola básica. Longe de ser uma noção elementar, ela se ampara em outras noções, tais como a de aplicação, de correspondência biunívoca, de relação de equivalência e de ordem. Na criança pequena, o número é indissociável da noção de medida. A possibilidade de fazer adições é que dá à noção de número seu caráter específico em relação às noções sobre as quais ela se baseia (VERGNAUD, 2009, p. 125). Neste sentido, Kamii defende a adição como um objetivo, pois

Somar números de um dígito é natural para as crianças pequenas. Quando elas constroem conceitos numéricos, a adição é parte desta construção, porque todos os números são criados pela adição repetida de um. Por exemplo, sete é formado fazendo-se $1+1+1+1+1+1+1$, adicionar um a isto forma oito, e assim por diante (KAMII, 2002, p. 83).

Dessa forma, ressaltamos que a construção do número está diretamente ligada ao desenvolvimento da contagem, que é, por sua vez, a primeira estratégia para a resolução de problemas empregada pelas crianças. E, como Kamii (2002) e Vergnaud (2009) asseguram, as crianças pequenas entre quatro a seis anos podem e devem resolver problemas para a construção de conceitos matemáticos. Segundo Vergnaud, os primeiros problemas que as crianças conseguem resolver são os problemas do campo aditivo, isto é, que envolvem adição ou subtração, pois estão diretamente conectados à contagem enquanto estratégia de resolução. Assim, para aprender a contar, são necessários certos conhecimentos que corroboram para a construção do número e do campo aditivo. Cabe ressaltar que nosso estudo se volta para a concepção de professores sobre o papel da sequência numérica oral no processo de construção do número. E, como foi discutido anteriormente e enfatizado na última citação, este processo envolve o conceito de adição, que é um componente do campo aditivo.

Contudo, para construírem suas hipóteses sobre a ordem numérica até chegarem à contagem propriamente dita (cardinalização das quantidades), as crianças precisam conhecer e saber recitar a sequência numérica oral. Segundo Barbosa (2009), "aprender a sequência das palavras-número é a primeira de muitas competências de que as crianças necessitam para que possam avançar nas aprendizagens matemáticas relacionadas com os números e operações." Quando vivenciada simultaneamente com a contagem, "que é a primeira forma, muito rústica, de aplicação numérica que se possa imaginar" (VERGNAUD, 2009), é capaz de desenvolver no trabalho da Educação Infantil futuras aprendizagens matemáticas, no campo da aritmética e do cálculo mental. 
De acordo com Vergnaud (2009), quando a criança enuncia a sequência numérica, ela pode estar situada em dois níveis. O primeiro nível é o nível da simples recitação, em que a criança apenas "canta" os números, recitando as palavras-número na ordem em que conhece (um, dois, três...). Não podemos dizer que, neste nível, a criança sabe contar até tal número, pois ela ainda não faz relação entre a palavra e a quantidade de objetos. Neste nível existem falhas na sequência, as crianças costumam se enganar e recitar numerais repetidos, quando não sabem o sucessor do número que estão falando. No segundo nível, que Vergnaud (2009) denomina contagem propriamente dita, a criança relaciona a recitação da série a um dado conjunto de objetos, fazendo relação entre a sequência numérica falada e o conjunto de objetos.

A respeito do trabalho com a sequência numérica oral, a que se refere como sequência numérica verbal, Carvalho (2014) acrescenta:

(...) o trabalho com a sequência numérica é muito importante porque se a criança não souber a ordem das palavras-número não terá como controlar e coordenar os movimentos gestuais, visuais e vocais. Porém, entendo que esse trabalho é insuficiente se não for feito concomitantemente com a interação de 1 (CARVALHO, 2014, p. 33).

É por isso que Monteiro (2010) afirma que as crianças aprendem a recitar a sequência numérica desde muito pequenas, muitas vezes sem se referir a objetos externos. Afirma também que a criança pode recitar a sequência de modo bem particular e que a recitação oral da sucessão de números é um importante meio de aproximação com o sistema numérico. Todavia, a mesma autora nos alerta de que é preciso cuidado para se evitar a mecanização, sendo necessário que as crianças compreendam o sentido do que estão fazendo e tenham conhecimentos prévios para as novas aprendizagens. De acordo com o que vimos anteriormente sobre o conceito de número em Piaget, para a construção do número, a criança precisa além de ordenar mentalmente os objetos, incluí-los de forma hierárquica adicionando sucessivamente mais um. Este processo não é fácil e seu desenvolvimento dependerá das experiências partilhadas pelas crianças.

\section{O método}

Tendo como objetivo identificar o papel atribuído à sequência numérica oral por professores da Educação Infantil no processo de construção e aquisição do conceito de número, entendemos que nossa a pesquisa é qualitativa. Segundo Lüdke e André (2014), esse tipo de abordagem compreende a obtenção de dados descritivos, levantados diretamente pelo pesquisador no campo, onde a ênfase está no processo e se preocupa em retratar o entendimento dos participantes. 
Como método de pesquisa qualitativa, adotamos a pesquisa participante. Em junho de 2016, solicitamos à Secretaria Municipal de Educação de Duque de Caxias/RJ autorização para que fosse realizada a coleta de dados em turmas da Educação Infantil da Creche Municipal Professor João de Oliveira. A creche se encontra no município de Duque de Caxias, Baixada Fluminense, no Estado do Rio de janeiro, no $1^{\mathrm{o}}$ Distrito - centro da cidade e bem próximo da comunidade da Mangueirinha, considerada uma das mais perigosas do município. A creche também atende aos bairros vizinhos, por se localizar perto de transportes públicos. As cento e dez (110) crianças são prioritariamente de famílias oriundas do Nordeste ou de outras comunidades do Rio de Janeiro e da Baixada.

Concedida a autorização documental pela secretaria e notificada a unidade escolar em concordância, iniciamos o contato pessoal com as professoras, apresentando as pretensões devidas para esse trabalho. Houve o aceite espontâneo pelas quatro (4) professoras pretendidas. Tornaram-se, então, sujeitos de pesquisa, especificamente, uma professora de uma turma com crianças de um (1) ano, duas de duas turmas com crianças de dois (2) anos e outra de uma turma com crianças de três (3) anos. A escolha foi motivada pelo fato de as professoras serem regentes de turma e terem cinco (5) horas semanais para planejamento, sendo isso um facilitador para os encontros.

Para a coleta de dados, observamos a atuação das professoras, produzindo um diário de campo, e realizamos entrevistas semiestruturadas. Iniciamos a coleta em setembro de 2016 e concluímos em abril de 2017. Observávamos semanalmente uma hora de aula de cada professora e, mensalmente, no horário de planejamento, realizávamos as entrevistas semiestruturadas, que eram sempre gravadas e transcritas.

Já, para a análise do material coletado, apoiamo-nos na teoria de Análise de Conteúdo (AC) descrita por Moraes e Galiazzi (2014). Segundo os autores, esta é uma das metodologias de análise que não podem ser entendidas “...como conjuntos rígidos de procedimentos, mas como orientações, abertas, reconstruídas em cada trabalho" (MORAES e GALIAZZI, 2014, p. 141). Após examinar todo o material coletado, elaboramos categorias importantes como forma de orientar nossa análise: (1) Trajetória de vida e a relacionada a matemática; (2) Conhecimento dos documentos norteadores das práticas na Educação Infantil ; (3) Concepções dos professores ao conceito de número; (4) Importância da Sequência Numérica Oral; (5) Coleta das atividades facilitadoras para a construção do número e tendo como facilitador a Sequência Numérica Oral; (6) Reflexão das estratégias e instrumentos utilizado na prática dos professores. Neste artigo, enfatizamos a análise das categorias 1, 3 e 4. Vale ressaltar que aqui utilizamos nomes fictícios, com o consentimento por escrito de todos os envolvidos, sendo a pesquisa submetida ao comitê de ética. 


\section{Análise dos dados}

À luz de dados da experiência de vida das professoras pesquisadas com a Matemática, iniciamos apresentando as relações que elas estabelecem com esta disciplina, pois suas histórias como alunas e professoras compõem sua subjetividade e influenciam suas práticas de ensino de Matemática. De acordo com Tardif (2013, p. 36), a prática do professor é "como um saber plural, formado pelo amálgama, mais ou menos coerente, de saberes oriundos da formação profissional e de saberes disciplinares, curriculares e experienciais".

Nas histórias contadas das experiências vividas pelas professoras pesquisadas, apenas a professora Maria declarou ter um amor profundo pela Matemática, embora tenha escolhido a Biologia como formação na graduação e atue também como professora de Ciências em outro estabelecimento de ensino. Disse que ainda mantém uma relação muito grande com a Matemática, quando, ao ensinar Ciências em turmas de nono ano, trabalha uma introdução à Física e à Química. Complementando, declarou que o que a fez desistir de estudar Matemática na universidade foi ter tido professores muito ruins no Ensino Médio, o que pode ser comprovado na transcrição de sua fala a seguir:

Foi uma relação de amor profundo. Quase fiz Matemática. Sempre tirei notas boas, sempre gostei muito. Mas, no Ensino Médio, eu tive professores muito ruins, no curso normal. Aí eu fiz o pré-vestibular, eu queria outra área de estudo. Me apaixonei por outra área e acabei fazendo Biologia. (Maria, Duque de Caxias, 2016)

Já a professora Nádia percebe sua vida entrelaçada com a Matemática pelo viés da música. Segundo ela, a música permite desconstruir a ideia de que a Matemática é só número. Quando toca e lê partituras, ela também vivencia a Matemática. Além disso, ela contou, como podemos verificar na transcrição a seguir que, assim que entrou para a Rede Municipal de Ensino, participou de uma formação para o ensino da Matemática e isto foi de vital importância para sua prática na sala de aula:

Logo que eu passei para Caxias foi patrocinado pelo município um cursinho de quatro encontros, um mês, uma vez por semana, curso de 4 horas, que foi Matemática na sala de aula. Nessa época, assim, abriu um pouco o leque. Eu saí daquela coisa que Matemática é só número. (Nádia, Duque de Caxias, 2016)

Sobre a formação de professores, Tedesco (1998) afirma que um dos fatores determinantes da baixa qualidade do ensino é a precária formação dos professores. Embora a má formação do professor não seja a única causa para o fracasso escolar dos alunos em sua escolarização, também nos é notória a sua grande influência. Influência esta, reconhecida pela própria entrevistada. A formação continuada vem clarificar muitos questionamentos e 
lacunas da formação inicial que o professor em exercício poderá adquirir. Como visto no depoimento da professora Nádia, o professor da Educação Infantil ainda tem muitas dúvidas no que se refere aos conteúdos matemáticos. Tal constatação nos levou a inferir sobre as dificuldades enfrentadas por esta professora para diversificar suas aulas, uma vez que não tem pleno domínio do que é adequado ou não para os seus alunos. Este é mais um dos motivos pelo qual se faz urgente a efetivação de uma formação continuada. Infelizmente, de acordo com Vasconcellos (1995) e Pires (2015), muitos dos cursos de graduação (quase na sua totalidade) não se prestam a fazer seu papel: ser um centro de formação e criação de conhecimento, de pesquisa e questionamento, o que provoca uma "formação deficitária; dificuldade em articular teoria e prática: a teoria de que se dispõe, de modo geral, é abstrata, desvinculada da prática e, por sua vez a abordagem que faz da prática é superficial, imediatista não crítica” (VASCONCELLOS, 1995, p. 19).

Já no que concerne à formação continuada de qualidade, precisamos ter políticas públicas que garantam o direito de aprender dos professores em exercício. Acreditamos que o melhor lugar para esta formação seja em lócus como garantem Nacarato e Paiva (2008), Fiorentini (2006) e Serrazina (2004), que apresentam modelos de formação continuada voltados para o contexto da escola, cujo propósito é o de investigar a prática do professor e a formação dos professores que ensinam Matemática. Formação esta, reflexiva de sua pratica, como comenta Kramer:

Fundamentalmente, é importante perceber que a efetiva formação do professor em serviço se dá através do confronto entre a reflexão sobre os conhecimentos advindos da sua prática e as teorias que explicam, questionam, lançam conflitos e indagações e permitem melhor compreender essa mesma prática (KRAMER, 1995, p. 99).

A professora Nádia também sinalizou que, comparando a Educação Infantil com o Ciclo de Alfabetização, nos dois níveis a alfabetização ganha destaque em detrimento das outras áreas de conhecimento. Para ela, se o professor não se 'policiar', a Matemática vai ficando de lado, mesmo sabendo que ela está inserida no nosso dia a dia. No dia a dia, ela gosta, se identifica e aplica a matemática. Disse que temos que aplicar, porque na nossa vida o tempo todo encontramos a Matemática. A partir das discussões vivenciadas na entrevista semiestruturada, Nádia também se comprometeu a ter um olhar mais atento e ampliar a quantidade de atividades de Matemática no planejamento das aulas de suas turmas, o que podemos comprovar na transcrição de sua fala:

Fazendo uma comparação daqui que é Educação Infantil com o ciclo que eu trabalho na outra escola, eu vejo que quando a gente começa a fazer o nosso planejamento, você vê que tudo que envolve alfabetização é voltado para o alfabeto, as palavras, as listas. E o conteúdo da Matemática, se a gente não 
tiver um policiamento, um controle, ele vai ficando assim de lado, mesmo a gente sabendo que ele está inserido num contexto bem mais amplo, bem maior (Nádia, Duque de Caxias, 2016).

O resultado disso é verificado nas salas de aula de Educação Infantil e dos anos iniciais do Ensino Fundamental. Muitas vezes a Matemática é deixada de lado, deixada para depois. A prioridade é alfabetizar. Assim, pensa-se que a Matemática pode esperar. E quando é trabalhada, consiste no ensino de sequências numéricas, de regras prontas, de contas armadas, o que evidencia os equívocos relacionados ao ensino da Matemática descritos por Monteiro (2010). Não raras vezes a preocupação de nossos professores em obter bons resultados em relação à escrita e à leitura dos alunos, no futuro, faz com que a alfabetização matemática seja esquecida, desde a inserção das crianças na escola, isto é, desde a creche. No entanto, sabe-se que esta é tão importante quanto a outra forma de alfabetização, sendo que ambas podem e devem ser trabalhadas em consonância para obtermos como resultado uma significativa melhora no processo de ensino como um todo dos alunos. Nesse sentido, defendemos uma formação que conscientize o professor da importância da aprendizagem matemática para o desenvolvimento cognitivo do aluno. Tal consciência implicará não só no aumento da carga horária destinada à Matemática, mas também na revisão de métodos de ensino.

A professora Ana disse não se identificar muito com a Matemática, que prefere a língua. Disse ainda que aprende a trabalhar Matemática ao mesmo tempo em que ensina e que não tem como fugir da Matemática no dia a dia da sala de aula, o que é mostrado na transcrição de sua fala: "Eu também nunca me identifiquei muito não. Procuro sempre estar aprendendo, né? Porque a gente aprende ao mesmo tempo que ensina.” (Ana, Duque de Caxias, 2016).

Tardif (2007) nos alerta que, se acreditamos que os professores são competentes e ativos, devemos admitir que a prática dos professores é um espaço de produção de saberes particulares que nascem dela. Esse saber deve ser valorizado, mas ampliado com o conhecimento científico para que sirva como ferramenta para uma prática mais consistente.

A professora ainda disse que se surpreende muitas vezes com os alunos. Num dia, ao propor uma atividade precisou dividir palitos de picolé e distribuiu os palitos sem contá-los. Grande foi sua surpresa ao perceber que um aluno a acompanhava e estimava a quantidade distribuída:

Você sabia que muitas vezes a gente se surpreende com as crianças? Eles sabem. Eu contei e tinha uns 30 palitos para cada um. Tem aluno que surpreende. E você vê que aquele ali vai escolher a matemática para a vida dele. Aí ele olhou e perguntou: tem trinta aí? Eu disse: tenho que botar mais, né? (Ana, Duque de Caxias, 2016) 
Entre alunos e professores há uma crença de que aprender Matemática é privilégio de alguns, aqueles que têm facilidade com os números e com as deduções lógicas. Na fala transcrita anteriormente reconhecemos a ideia de que somente alguns têm aptidão para a Matemática. Esta é uma crença do senso comum, mas não é verdadeira. É preciso, sim, buscar caminhos para que as crianças adquiram uma atitude de interesse e inquietude frente ao conhecimento. Assim como Monteiro (2010), partimos do pressuposto de que, sob certas condições, todos podem aprender Matemática. Além disso, o baixo desempenho pode afetar a autoestima do estudante e distanciá-lo cada vez mais da Matemática.

Oferecendo um exemplo do que acabamos de afirmar, a professora Flávia comentou que escolheu uma carreira fora do magistério só para fugir da Matemática. Disse ter pavor, principalmente por ter tido uma professora em especial que a traumatizou. Afirma que diariamente convivemos a todo o momento com a Matemática, que todos os setores convergem para a Matemática, seja nas diversas áreas de conhecimento, seja nos afazeres cotidianos. Na transcrição a seguir, ela declara que a Matemática está tão presente em nossas vidas que nem percebemos quando a usamos:

$\mathrm{Na}$ verdade eu fui fazer uma faculdade completamente diferente da Educação para fugir da Matemática. Eu tenho pavor! A minha professora me traumatizou muito. Mas não tem jeito, todos os setores convergem para a Matemática. Seja a leitura, seja em ciências, seja o dia a dia no mercado, enfim, a Matemática eu vejo como uma forma automática na vida (Flávia, Duque de Caxias, 2016)

Esta fala confirma os resultados de Starepravo (2006, p. 9) de que não é raro ouvirmos alunos e alunas dos cursos de Pedagogia ou Normal Superior dizer que suas escolhas representaram um grande alívio por afastá-los da disciplina que sempre foi a mais difícil e que mais lhes causou frustração, a Matemática.

De acordo com Sadovsky (2007), as frustrações podem decorrer do fato de a escola abordar a Matemática de forma superficial e mecânica. Para a autora, falta formação aos docentes para aprofundar aspectos mais relevantes que possibilitam considerar os conhecimentos prévios dos alunos, as situações didáticas e os novos saberes em construção. No caso específico deste estudo podemos citar, por exemplo, os aspectos relativos ao processo de construção do número e dos principais conceitos imbricados nesse processo, como a contagem, a sequência numérica oral, a adição e a subtração. O docente precisa ter uma postura reflexiva, pois só lançar o conteúdo não é o suficiente para que seus alunos aprendam. É preciso uma bagagem conceitual sólida para tomada de decisões, quer sejam individuais ou coletivas. 
Tendo vivenciado como estudantes um ensino mecanizado da Matemática e tendo recebido uma formação que pouco ou nenhum impacto causou sobre estas experiências, os professores tendem a perpetuar concepções e práticas equivocadas sobre a Matemática e seu processo de ensino e aprendizagem. Nos sujeitos de nossa pesquisa, isso foi facilmente verificável em suas práticas e concepções sobre a construção e aquisição do conceito de número. Sobre a conceitualização do número, todas as professoras entrevistadas definiram que o que caracteriza se uma criança construiu este conceito é o fato de ela conseguir relacionar o número ao algarismo. Nas palavras da professora Ana: é quando a criança identifica a quantidade (Flávia, Duque de Caxias, 2016).

Além destas palavras, as práticas mencionadas pelas professoras como exercícios de escrita dos algarismos em situações de passar o lápis sobre numerais pontilhados, colagem de bolinhas de papel crepom sobre numerais, cópias repetidas de um mesmo numeral e escrita repetida da sucessão numérica, sinalizaram que as professoras acreditavam erroneamente que, quando a criança está nomeando o algarismo, ela já construiu o conceito numérico. Porém, muito mais do que isso, o número consiste em conhecimento lógico-matemático, isto é, para conceituá-lo é preciso estabelecer relações mentais. Como afirma Kamii $(2003,19)$, "as crianças constroem o número internamente, em vez de aprender a reconhecê-lo como se fosse algo disponível para ser reconhecido empiricamente”. Entretanto, o que está por trás destas formas mais comuns de tentar ensinar números na Educação Infantil é a crença de que o conceito de número pode ser transmitido via oral e memorizado pela criança, por meio de exercícios gráficos. Parece que se ignora, em âmbito escolar, o que é conhecimento físico e conhecimento lógico-matemático, o que provoca a falta de diferenciação entre número e numeral por parte de pais e professores. Assim, pais e professores desconhecem que "na linguagem matemática, os numerais são as representações gráficas da quantidade enquanto que os números são as relações mentais (psicológicas) que se estabelecem entre as quantidades do mundo físico em que vivemos" (SCRIPTORI, 2010, p.135). Isto é, a aprendizagem do número exige compreensão e não memorização de dados.

Quando foram indagadas sobre a importância da sequência numérica oral para a construção do conceito de número pela criança, as professoras não souberam responder. Disseram que trabalham a sequência oralmente com as crianças, mas que muitas vezes executam atividades na sala de aula sem saber os porquês, atuando intuitivamente. Disseram que aprender a sequência numérica ajuda no posterior reconhecimento do algarismo, o que se verifica na transcrição da fala da professora Ana "Não sei da importância. Tem muita coisa que a gente trabalha e é só através do estudo mesmo que a gente tem noção. Às vezes você usa muita coisa na prática. A gente faz intuitivamente" (Ana, local, Duque de Caxias, 2016). 
Contudo, uma vez mais destacamos que o recitado convencional da sucessão ordenada de números tem um papel fundamental no início das aprendizagens numéricas, pois a partir desse conhecimento as crianças vão aprendendo as leis internas que organizam o sistema. Nessa direção, Monteiro (2010) salienta que as atividades precisam ter sentido para as crianças, ajudá-las a adquirir a sucessão convencional de números e paulatinamente ampliá-la.

Sobre este tema, a professora Nádia comentou que apenas saber a sequência dos algarismos e ter seu registro na sala de aula não garante a aprendizagem da noção de número: Só olhar, não. Mas vivenciar ali no concreto (Nádia, Duque de Caxias, 2016). Ela também alertou que o fato de algumas crianças saberem uma parte da sequência numérica oral, não quer dizer que sabem sua quantificação:

A minha turminha de 3 anos, quando a gente começa a trabalhar qualquer coisa que tem uma sequência tanto no concreto quanto no abstrato, se eu deixar, eu tenho alunos que vão seguindo adiante Eu tenho um aluno que chega ao 15, que chega ao 16, mas ele não sabe o que é que ele representa. (Nádia, Duque de Caxias, 2016)

Percebemos que as palavras desta professora vão ao encontro de Scriptori (2011) quando afirma que, se uma criança repete oralmente os numerais em uma dada ordem não significa que ela tenha compreendido o que os números significam do ponto de vista da Matemática, isto é, o conceito de número. Significa apenas que a criança está tentando dar um sentido às verbalizações que ouve no meio em que vive, buscando dar um sentido social aos números que permeiam sua vida.

As atividades para sequência numérica oral que as professoras pesquisadas mais elencaram são as atividades que aparecem no cotidiano, que não são intencionais para ensinar a sequência numérica. São elas: chamadinha, calendário, organizar coisas, dividir brinquedos e objetos e cantar músicas com a sequência numérica. Todas as professoras disseram que aproveitam situações do dia a dia para trabalharem a sequência numérica oral. Uma recorrência em todas as falas foi o destaque para a contagem diária das crianças para merenda. Uma professora conta que todos os dias uma "tia" entra na sala e pergunta quantos alunos vieram. Que eles participam ativamente desta contagem. E afirmam ser muito interessante vê-los contando, tentando antecipar o número exato de crianças. Legitimando esta prática das professoras, Monteiro (2010, p. 9) garante que "as situações da rotina da Educação Infantil nas quais os números adquirem sentido também podem ser aproveitadas como um contexto de aprendizagem numérica”.

Ao visitarmos as salas, observamos que, em todas, existe afixada na parede a sequência numérica escrita até 9 com sua respectiva correspondência numérica. É 
importante salientar que é preciso ampliar os aportes numéricos como também as escalas dos números trabalhados em sala de aula pelos professores da Educação Infantil. Se as crianças de Educação Infantil só trabalharem com números de 1 a 9, não poderão colocar em jogo esses conhecimentos, não chegarão a utilizar o critério da quantidade de algarismos para saber se um número é maior ou menor que outro. Para que as crianças possam construir essas hipóteses, é necessário ampliar a escala dos números com os quais se trabalha na Educação Infantil.

Em síntese, as crianças precisam participar de situações de uso dos números, de análise das regras que regem o sistema de numeração escrito para poderem estabelecer regularidades. Se não tiverem a oportunidade de ver que isso sucede entre diferentes grupos de números, não será possível construir esse conhecimento (MONTEIRO, 2010). É necessário que as crianças vivenciem várias situações relacionais, mas também é muito importante ter uma sala ambientada para uma alfabetização matemática, para que esses portadores sirvam como fonte de informação (SCRIPTORI, 2011). É fundamental incluir, em todas as salas, diferentes portadores numéricos como calendários, fita métrica, quadro numérico, calculadora, que funcionem como fonte de informação, um tipo de "dicionário" que está à disposição da criança para que possa consultá-lo sempre que precisar, o que contribui também para o desenvolvimento de sua autonomia.

\section{Considerações finais}

Neste artigo tivemos como objetivo identificar o papel que um grupo de quatro professoras de uma creche municipal de Duque de Caxias/RJ atribui à sequência numérica oral no processo de construção e aquisição do número. Observamos desde o início de nossa pesquisa de campo que as práticas e concepções sobre a sequência numérica oral estão estreitamente relacionadas às práticas e concepções sobre o processo de conceitualização do número e estas, por sua vez, sofrem influência das relações que as professoras estabelecem com a própria Matemática.

Independentemente de gostar ou não da Matemática, em suas falas, todas as professoras evidenciaram ter vivido como estudantes um ensino bastante mecanizado, fundamentado na memorização de procedimentos e técnicas. Tal vivência vai se refletir no modo como concebem a conceitualização do número: elas restringem este processo à associação entre o número e sua representação com algarismos. Assim, desprezam as relações de ordem e inclusão hierárquica, definidas por Piaget e seus seguidores como fundamentais para a construção da noção de número.

Com relação à sequência numérica oral, todas reconhecem que ela desempenha um papel importantíssimo para a contagem e, consequentemente, para a construção do número. 
Entretanto, a prática de limitar a sequência numérica oral até 9 impede que esta cumpra plenamente a função de permitir que as crianças observem padrões numéricos.

Cabe mencionar, ainda, que as professoras reconhecem que o domínio da sequência numérica oral não é garantia da construção do número, no entanto, não conseguem fundamentar seus pontos de vista. Assim como quando explicam as tarefas que costumam valorizar para o ensino do número e da sequência numérica, afirmam agir e tirar conclusões instintivamente. É aí que destacamos a necessidade de uma formação continuada. Acreditamos que uma formação que permita às professoras refletir sobre suas práticas favorecerá o abandono de práticas equivocadas e fortalecerá práticas adequadas. Dessa forma, investigar como deve ocorrer esta formação é uma sugestão para pesquisas futuras. Entendemos que pensar o lugar do ensino da Matemática na Educação Infantil se constitui processo e caminho para um lugar emancipador dos sujeitos e suas aprendizagens. Por ser a Matemática ainda fonte de exclusão social é importante lutarmos para que a educação possa ser de excelência e garantida para todos desde o início da inserção dos alunos na vida escolar, isto é, desde a Educação Infantil.

\section{Referências}

BARBOSA, E. P. M. O. A sequência numérica verbal de crianças na transição do pré-escolar para o primeiro ciclo. Porto:2009. (Dissertação de mestrado).

BARBOSA, M. C. S. Práticas cotidianas na Educação Infantil: Bases para a reflexão sobre as orientações curriculares. Brasília: Ministério da Educação, 2010.

As especificidades da ação pedagógica com bebês. Brasília: Ministério da Educação, 2010.

BRASIL. Referencial Curricular Nacional para a educação infantil. Brasília: MEC/SEF, v. 1 e v. 3, 1998.

- LDB - Lei de Diretrizes e Bases da Educação Brasileira. Disponível em: http://www.planalto.gov.br/ccivil_03/leis/L9394.htm. Acesso em 2016.

BRIZUELA, B. Desenvolvimento Matemático na Criança: Explorando Notações. Porto Alegre: Artmed, 2006.

CARVALHO, M. Aprender a contar e a resolver problemas matemáticos na educação infantil. In: CARVAlHO, M.; BAIRRAL, M. A. (Orgs.) Matemática e educação infantil: investigações de práticas pedagógicas. Petrópolis, RJ: Vozes, 2014.

KAMII, C.; HOUSMAN, L. Crianças pequenas reinventam a aritmética. Porto Alegre: Artmed, 2002.

KAMII, C.; DEVRIES, R. Jogos em grupo na educação infantil: implicações da teoria de Piaget. São Paulo, Artmed, 2007. 
A criança e o número: implicações educacionais da teoria de Piaget para atuação junto a escolares de 4 a 6 anos. Campinas, SP: Papirus, 2003.

LERNER, D.; SADOVSKY, P. O sistema de numeração: um problema didático. In: PARRA,C.;SAIZ,I.(Orgs.)Didáticadamatemática:reflexõespsicopedagógicas.Porto Alegre: Artmed, 1996. p.73-156.

LUDKE, M.; ANDRÉ, M.E. Pesquisa em Educação: Abordagens qualitativas. $2^{\mathrm{a}}$ ed. - Rio de Janeiro, RJ: E.P.U, 2014.

MOURA. M. O. Saberes pedagógicos e saberes específicos: desafios para o ensino de matemática. In: SILVA, A. M. M.; et al. Encontro Nacional de Didática e Prática de Ensino. Novas subjetividades, currículo, docência e questões pedagógicas na perspectiva da inclusão social. Recife. ENDIPE, 2006. P. 489 - 504.

MONTEIRO, P. As crianças e o conhecimento matemático: experiências de exploração e ampliação de conceitos e relações matemáticas. Anais do primeiro seminário Nacional: Currículo em movimento, Belo Horizonte, 2010. p. 1-17.

MUDIM, J.; SARAMAGO, G. A presença da matemática na educação infantil, enfoques e desafios. In: IV Colóquio Internacional Educação e Contemporaneidade, Minas Gerais, 2009

PANIZZA, I. Ensinar Matemática na Educação Infantil e nas Séries Iniciais. Porto Alegre: RS. Artmed, 2006.

PIAGET, J. A gênese do número na criança. Rio de Janeiro: Zahar, 1973.

PIAGET, J. SZEMINSKA, A. A gênese do número na criança; trad. Christiano Monteiro Oiticica. Rio de Janeiro: Zahar Editores, 1975.

PIRES, C. M. C. . Reflexões sobre Relações entre Currículo, Avaliação e Formação de Professores na Área de Educação Matemática. BOLEMA: Boletim de Educação Matemática (Online) , v. 29, p. 473-452, 2015.

SADOVSKY, P. Falta Fundamentação didática noensino da matemática. Nova Escola. São Paulo, Ed. Abril, Jan./Fev. 2007.

SCRIPTORI, C. C. Pressupostos para o trabalho docente com a matemática na educação infantil. In: BESSA, S. O desafio de ensinar e aprender matemática na educação básica. Campinas, SP: FE/Unicamp; Metaprint, 2011. p. 205-222.

TARDIF, M. Saberes docentes e formação profissional. Petrópolis, RJ: Vozes, 2013.

TEDESCO, J.C. O novo pacto educativo: educação, competitividade e cidadania na sociedade moderna. São Paulo: Ática, 1998.

VASCONCELLOS, C.dos S. Para onde vai o professor? Resgate do professor sujeito de transformação. 13 a ed. São Paulo: Coleção Subsídios Pedagógicos, Libertad, 2008. 
VERGNAUD, G. A criança, a matemática e a realidade: problemas do ensino da matemática na escola elementar. Curitiba: Ed UFRP, 2009.

\section{Biografia Resumida}

Heloise de Araujo Albuquerque: Mestre em Educação. Professora da Secretaria Municipal de Educação de Duque de Caxias - Rio de Janeiro, Brasil.

e-mail: ahelousealbuquerque@globo.com

Ophelio Walkyrio de Castro Walvy: Doutor em Educação pela Universidade Federal Fluminense. Professor do Instituto Federal de Educação, Ciência e Tecnologia do Rio de Janeiro.

Link do Lattes: http://lattes.cnpq.br/9251892888361510 e-mail: ophelio.walvy@ifrj.edu.br

Gabriela dos Santos Barbosa: Doutora em Educação Matemática pela PUC/SP, pós-doutora pela PUC/SP e pela UFRJ. Professora Adjunta e coordenadora do curso de Licenciatura em Matemática da Universidade do Estado do Rio de Janeiro (UERJ), campus Duque de Caxias.

Link do Lattes: http://lattes.cnpq.br/4376993135659619

e-mail: gabrielasb8o@hotmail.com 